\title{
Characteristics of the Intermediates in the Cyclization Reactions of Heterocycle-fused[1,4]oxazine Derivatives: Stepwise versus Concerted
}

\author{
Dong-Soo Shin ${ }^{\dagger}$ and Jong Keun Park \\ 'Department of Chemistry, Changwon National University, Changwon 641-773, Korea \\ Department of Chemistry Education, Research Institute of Natural Science, and Educational Research Institute, \\ Gyeongsang National University, Jinin 660-701, Korea. "E-mail: mc7@gmiac.kr
}

Received June 8, 2007

\begin{abstract}
The reaction mechanisms for the cyclizations of $N$-methyl-2-(2-chloropyridin-3-yloxy) acetamide to 1-methylpyrido[3,2-b][1,4]oxazin-2-one and 1-methyl-pyrido[2,3-b][1,4] oxazin-2-one were investigated using ab initio IIartree-Fock, second-order Moller-Plesset perturbation, single point coupled cluster with both single and double substitution, and density functional theory methods. The 5 -membered spiro intermediate (2) is optimized from the cyclization of the acyclic reactants through the proton-transfer reaction, and this intermediate proceeds continuously to the 6-membered intermediate through either a stepwise or a concerted reaction. In the stepwise reaction, an $N$-bridge-type intermediate as a stable structure is optimized, whereas, in the concerted reaction, the $O$-bridge-type intermediate is not optimized.
\end{abstract}

Key Words : Geometrical structure, Cyclization reaction, Stepwise reaction, Concerted reaction, Smiles rearrangement

\section{Introduction}

Significant and valuable synthetic methods based on the Smiles rearrangement have been developed and widely applied for the synthesis of cyclic and acyclic systems..$^{1-20}$ Because benzo-fused and heterocyclic products were recognized as potential bioactive, phammaceutical, and medicinal materials, many studies focused on their synthesis. Particularly, benzo $[1,4]$ oxazines, ${ }^{1}$ pyrido[ $[3,2-b][1,4]$ oxazines, ${ }^{2-8}$ and pyrimido $[5,4-b][1,4]$ oxazines ${ }^{9}$ were produced using the synthetic methods based on the Smiles rearrangement. Although effective synthetic methods for cyclic and acyclic systems have been developed using the Smiles rearangement, ${ }^{10-12}$ the reaction mechanisms for these syntheses have been experimentally explained by two or three stepwise mechanisms including the Smiles rearrangement and the cyclizations.

Recently, in the cyclization reactions, ${ }^{7.8}$ benzo- and pyrido $[1,4]$ oxazines were directly synthesized from alkyl 2- halopropionates with 2-amino-3-hydroxypyridine using rearrangement. However, the pyrido $[2,3-b][1,4]$ oxazines were not directly synthesized from the reactants. The reaction mechanisms for these syntheses were explained using a three-step process (alkylation, Smiles rearrangement, and rapid cyclization). Recently, in the experiment carried out by Bonini et $a{ }^{11}$ and Mizuno and Yamano, ${ }^{12}$ the conversions of phenols to anilines were also explained using a three-step process. In the experiments of Balko and Brinkmeyer, ${ }^{13}$ Heilmann and Sicker, ${ }^{14}$ Erickson and McKennon, ${ }^{15}$ Kimbaris et $a L_{.}{ }^{16.17}$ and Guillaumet et $a l .{ }^{3-5}$ the Smiles rearrangement did not take place under mild conditions (weak acid and low temperature). However, under strong conditions (strong acid and high temperature), the products of the rearrangement were observed in low yields. In the radical mechanism suggested by the Zard group, ${ }^{18}$ the transition state of the Smiles rearrangement was explained on the basis of three separate transition steps including an electron. The middle transition state was represented through a structure with a 4-

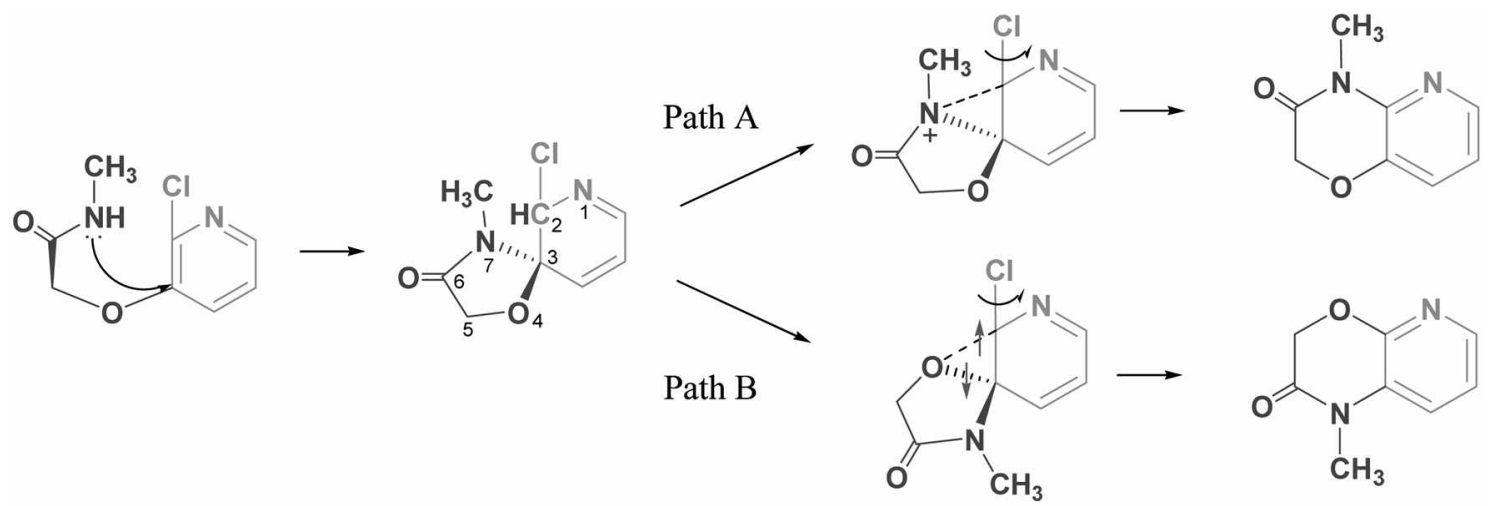

Scheme 1. Possible cyclization reactions: stepwise (Path A) and concerted (Path B) mechanisms. 
membered ring.

Although the various synthetic methods based on the Smiles rearrangement have been extensively developed and applied, the reaction mechanisms for the cyclization reactions of heterocycle-fused[1,4] oxazine derivatives have not been cleared so far. In the present work, we have studied the the reaction mechanisms for the cyclization reactions based on the Smiles rearrangement. Firstly, the geometrical structures and relative energies for the cyclization reactions of heterocycle-fused[1,4]oxazine derivatives were investigated. Secondly, the potential energy curves for the angular variations from the 5-membered intermediates to the 6membered rings were examined to clarify the reaction mechanisms for the cyclization reactions. Lastly, the potential energy curves from the acyclic reactants to their cyclic intermediates were calculated to elucidate the cyclization reaction paths and to examine the internediate species for the previously suggested synthetic routes.

\section{Calculational Methods}

The equilibrium geometrical structures of $N$-methyl-2-(2chloropyridin-3-yloxy)acetamide, 1-methyl-pyrido[3,2-b][1,4] oxazin-2-one, 1-methyl-pyrido[2,3-b][1,4] oxazin-2one, and their intermediates were fully optimized with the $a b$ initio Hartree-Fock (HF), second-order Möller-Plesset perturbation (MP2), single-point coupled cluster with both single and double substitution $[\operatorname{CCSD}(t)]$, and density functional theory (DFT) methods with standard basis sets ( 6 $31 \mathrm{G}^{*}, 6-31+\mathrm{G}^{* *}$ ) using the Gaussian $03 .^{21,22}$ The density functional theory (B3P86) uses Becke's 3 parameter-hybrid functional in conjunction with the nonlocal correlation provided by the Perdew 86 expression. ${ }^{23-27}$ To confirm the existence of stable and unstable structures (ground, intermediate, and transition states), the harmonic vibrational frequencies of the species were analyzed at the MP2/6-31G* level. The optimized geometrical structures and the relative energies for the cyclization reactions from the acyclic reactant to the cyclic product at the single-point CCSD(t)/6$31+\mathrm{G}^{* *}$ level (after MP2/6-31+G*) were optimized and evaluated, respectively (Figures 1,3 ). The potential energy curves from the reactant to the product are calculated using the total energies as a function of the $\mathrm{N}_{7} \mathrm{C}_{3} \mathrm{C}_{2}\left(\mathrm{O}_{4} \mathrm{C}_{3} \mathrm{C}_{2}\right)$ angles, in the range from 15.0 to 130.0 degrees, using the MP2/6-31+G** level (Figure 2). To investigate the position of the proton-transfer and the energy barrier of the Smiles rearrangement, the potential curves for the cyclization from the anionic reactant to the product were calculated for $\mathrm{R}_{\mathrm{N} 7 \mathrm{C}} \mathrm{C}$ values ranging from 4.0 to $1.2 \AA$ using the MP2/6-31+G** level (Figure 4). After the rearrangement, the potential energy curves for the recyclizations were also calculated for $\mathrm{R}_{(\mathrm{S}-\mathrm{C} 3}$ ) values ranging from 1.3 to $2.9 \AA$ using the $\mathrm{B} 3 \mathrm{P} 86 / 6$ $31+\mathrm{G}^{* *}$ level (Figure 5).

\section{Results and Discussion}

The geometrical structures and the relative energies for the cyclization reactions from $N$-methyl-2(2-chloropyridin-3yloxy)acetamide to 1-methyl-pyrido[3,2-b][1,4]oxazin-2one (Path A) and 1-methyl-pyrido[2,3-b][1,4] oxazin-2-one (Path B) are shown in Figure 1. Firstly, the spiro compound (2) as a stable intermediate is optimized with ring closure between $\mathrm{N}_{7}$ of the amide group and $\mathrm{C}_{3}$ on the pyridine group. In the intermediate (2), a 6-membered ring perpendicularly binds to a 5 -membered ring. The intermediate of (2) changes to an $N$-bridge-type intermediate (A) along the potential energy surface. The triangle formed by the sandwich in (A) is vertically located between the 5- and 6membered rings. Meanwhile, a transition state exists between (2) and (A). To form this transition state, a novel ring closure occurs by $\left(\mathrm{N}_{7} \cdots \mathrm{C}_{2}\right)$ bond formation in (2) and simultaneously a chloride disconnects from the $\mathrm{C}_{2}$ carbon. After passing through the transition state, a stable intermediate (A) without the chloride is optimized. The intermediate (A) is relatively stable and the relative energy between it and the product is $67.75 \mathrm{kcal} / \mathrm{mol}$. To reduce the ring strain, the 5-membered ring of (A) changes into a 6membered ring, and then the structure of $(\mathbf{B})$ is optimized. By the deprotonation of $(\mathbf{B})$, the internediate finally evolves to become the product $(\mathbf{C})$. The aromaticity of the 6membered ring in $(\mathbf{C})$ is reformed and the product becomes more stable. Because of the aromaticity of $(\mathbf{C})$, the energy gap $(53.46 \mathrm{kcal} / \mathrm{mol})$ between (B) and (C) is relatively large. The relative energy between the reactant and the product is nearly isoenergetic within $1.84 \mathrm{kcal} / \mathrm{mol}$.

Due to the intramolecular addition of the $\mathrm{O}_{4}$ oxygen to the $\mathrm{C}_{2}$ carbon in (2), the compound converts to an $O$-bridge-type transition intermediate (3). Then, a chloride in (3) is also disconnected from the $\mathrm{C}_{2}$ carbon and bound to two hydrogen atoms. The rearrangement and the cyclization reactions in (3) simultaneously proceed through the $O$-bridge-type intermediate. The angle between the 6-membered and the 5membered rings is about 100 degrees. Without the chloride, the intermediate (3) is not optimized as a stable structure. In (4), the two nitrogen atoms are oriented in opposite directions. The product (5) is formed from the deprotonation of (4), and then a double bond is formed in the ring. The relative energies of the product and the reactant are nearly the same. The energy gap of (3) with respect to (5) is 84.81 $\mathrm{kcal} / \mathrm{mol}$. In both Paths A and $\mathbf{B}$, the relative gap between the two product isomers (1-methyl-pyrido[3,2-b][1,4]oxazin-2-one and 1-methyl-pyrido[2,3-b][1,4] oxazin-2-one) is $1.61 \mathrm{kcal} / \mathrm{mol}$. Both products are more stable than the reactants. The reaction mechanism with $\mathbf{P a t h} \mathbf{A}$ is more energetically stable than that with Path B by $18.67 \mathrm{kcal} / \mathrm{mol}$.

To investigate the mechanisms for the Smiles rearrangement and the cyclization in more detail, we selected the 5membered spiro cation ( $\left.2^{\prime}\right)$ without a chloride as a model. The potential energy curves for the angular variations $(\varphi)$ from the 5 -membered spiro rings of $\left(2^{\prime}\right)$ to the 6 -membered rings $[(\mathbf{B}),(4)]$ at the MP2/6-31+G** level are shown in Figure 2. The intermediate (2') is a cationic compound with a singlet spin state which is a stable state with a shallow and broad well (energy barrier $=1.38 \mathrm{kcal} / \mathrm{mol}$ ) to $(\mathbf{A})$. The 


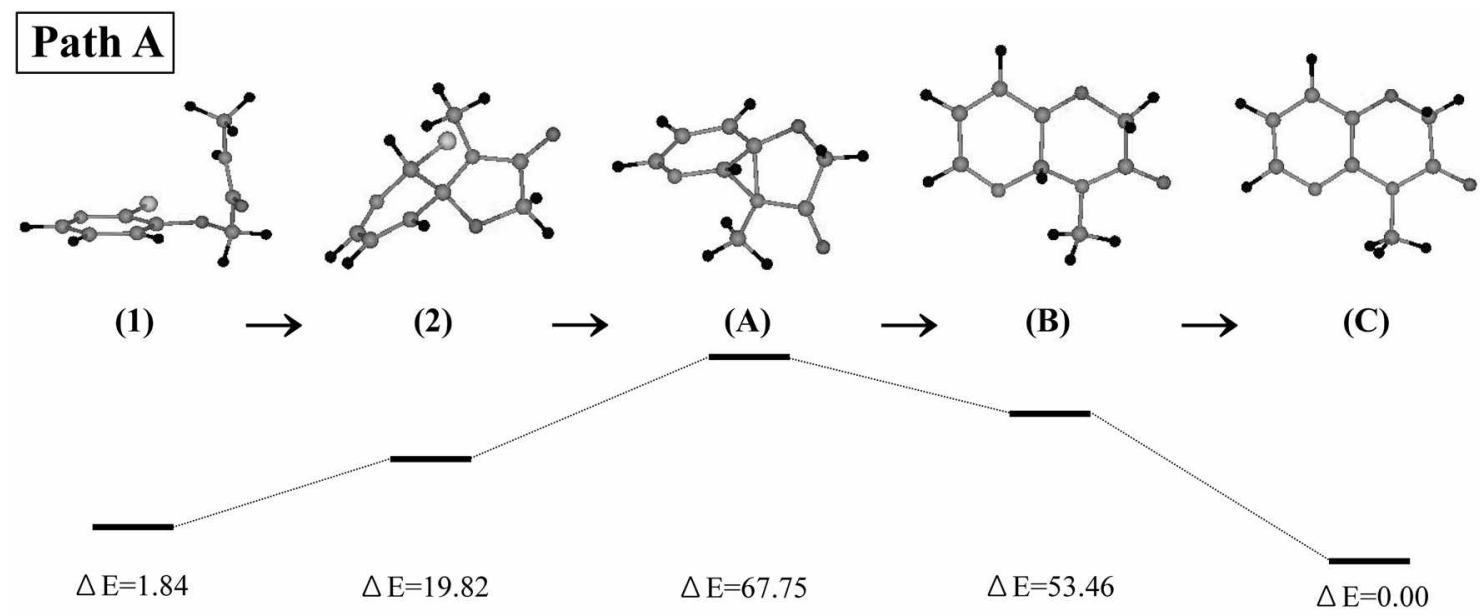

\section{Path B}

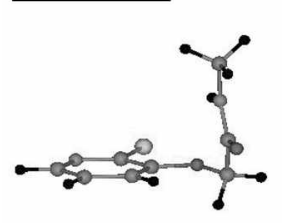

(1)

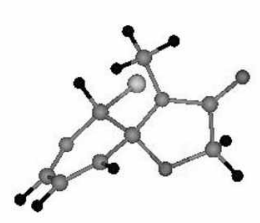

(2)

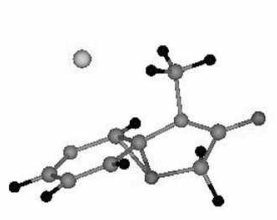

(3)

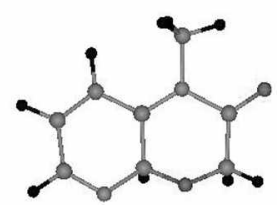

(4)

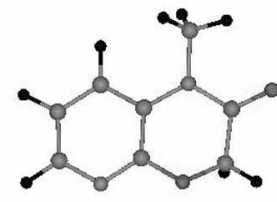

(5)

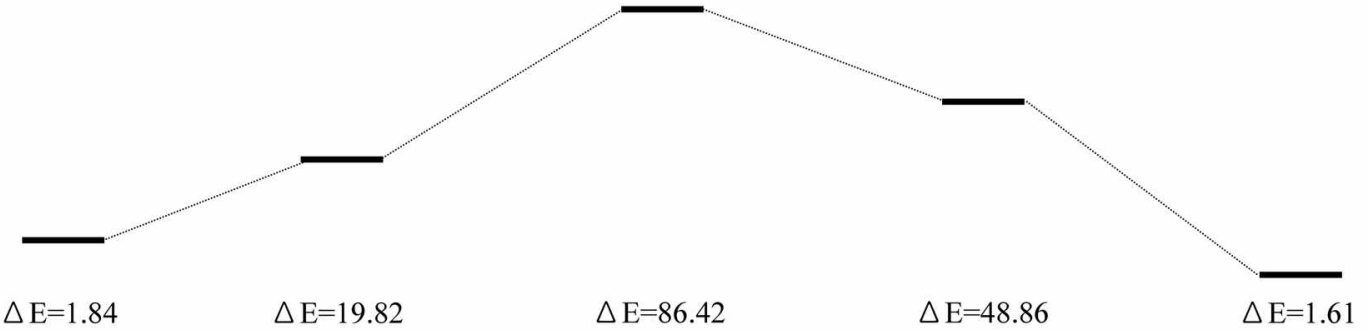

Figure 1. The optimized structures and relative energies for the cyclization reactions from N-methyl-2(2-chloropyridin-3-yloxy) acetamide to 1-methyl-pyrido[3,2-b][1,4]oxazin-2-one (Path A) and I-methyl-pyrido[2,3-b][1,4]oxazin-2-one (Path B) at the single point [CCSD(t)]/ $6-31+\mathrm{G}^{* *}$ level (after MP2/6-31+G**). The relative energies of $[(\mathbf{B}),(4)]$ and $[(\mathbf{C}),(5)]$ are cvaluated as the total energy including the potential energies of $\mathrm{Cl}^{-}$and $\mathrm{HCl}$, respectively. $(\mathrm{O}: \mathrm{H}, \mathrm{O}: \mathrm{C}, \mathrm{O}: \mathrm{N}, \mathrm{O}: \mathrm{O}, \mathrm{O}: \mathrm{Cl}$ )

structure of $\left(2^{2}\right)$ is similar to that of (2) without a chloride. First, to examine the synthetic mechanism of 1-methylpyrido[3,2-b][1,4]oxazin-2-one, the geometrical structures of $\left(2^{\prime}\right)$ are calculated for the angle $\left(\varphi, \angle \mathrm{N}_{7}-\mathrm{C}_{3}-\mathrm{C}_{2}\right)$ in the range from 130.0 to 25.0 degrees. The lone pair electron of the nitrogen atom $\left(\mathrm{N}_{7}\right)$ in $\left(2^{2}\right)$ interacts with the cationic carbon atom $\left(\mathrm{C}_{2}\right)$ on the 6-membered ring and then the $\mathrm{N}$ bridge-type intemnediate associated with the novel $\left(\mathrm{N}_{1} \cdots \mathrm{C}_{2}\right)$ bond formation is optimized. Around $\varphi=62.5$ degrees, the structure of (A) having a potential barrier of $0.92 \mathrm{kcal} / \mathrm{mol}$ is optimized. Along the potential curve, the 5-membered ring of (A) changes to a 6-membered ring. The transition states between (A) and (B) and between ( $\left.\mathbf{2}^{\prime}\right)$ and (A) are formed at $\varphi=55.1$ and 101.8 degrees, respectively. Finally, the geometrical structure of $(\mathbf{B})$ is optimized. The reaction from $\left(\mathbf{2}^{\prime}\right)$ to (B) proceeds through a stepwise mechanism. Experimentally, the Smiles rearrangement for the 1-methylpyrido[3,2-b][1,4]oxazin-2-one takes place under mild conditions (weak acid and low temperature). The reaction mechanisms for the reaction have been explained by three stepwise mechanisms including the Smiles rearrangement and the cyclizations. These suggested three stepwise processes are in good agreement with above calculated result including the three intermediates of (2), (A), and (B). Meanwhile, with an angular variation $\left(\varphi, \angle \mathrm{N}_{7}-\mathrm{C}_{3}-\mathrm{O}_{4}\right)$ ranging from 70 to 15 degrees, the $N$-bridge-type structure of $(\mathbf{A})$ changes into the internediate $(c)$ with a 7 -membered ring. That is, the $\left(\mathrm{C}_{3} \cdots \mathrm{C}_{2}\right)$ bond in (A) becomes disconnected. The potential energy surface has an energy barrier of 29.96 $\mathrm{kcal} / \mathrm{mol}$ and the energy gap from (A) to (c) is $17.51 \mathrm{kcal} /$ mol.

Second, to study the mechanism for the formation of 1methyl-pyrido[2,3-b][1,4]oxazin-2-one, the geometrica] structures of (2) are also optimized for angles $\left(\angle \mathrm{O}_{4}-\mathrm{C}_{3}-\mathrm{C}_{2}\right)$ ranging from 130.0 to 25.0 degrees. Around $\varphi=62.5$ degrees, the potential curve has a shoulder. However, it does not have a potential barrier. Although the structure of (3) in Figure $I$ is optimized, the structure of $\left(3^{*}\right)$ as a stable state is 


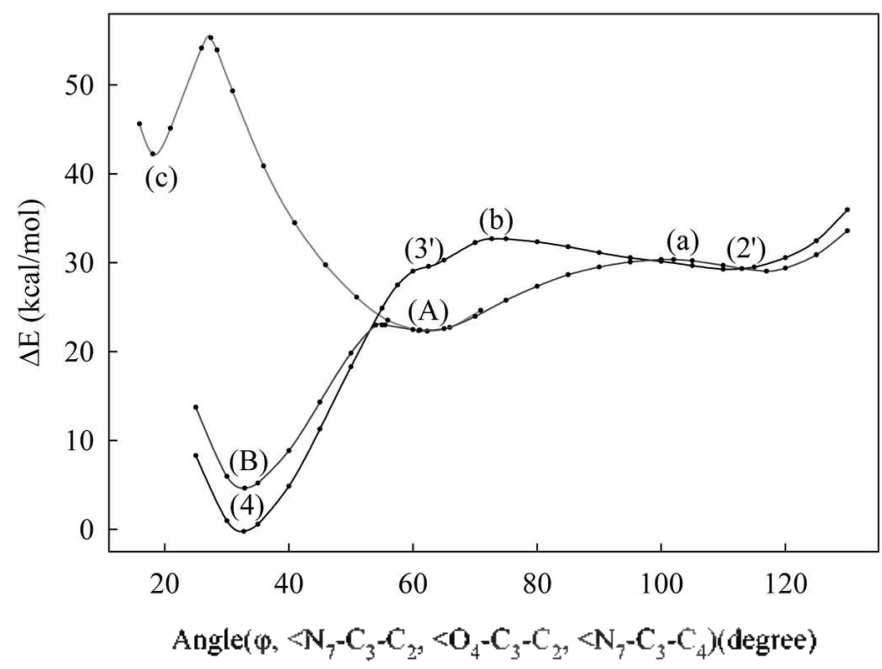

(2') :<smiles>CN1C(=O)CO[C@]12C=CC=NC2</smiles>

(3') :

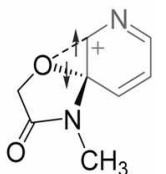

(4) :<smiles>C[N+]1=C2C=CC=NC2OCC1=O</smiles>

(A)<smiles>C[N+]1(C)OC2C1COC21C=CC=NC1</smiles>

(B) :<smiles>CN1C(=O)COC2=CC=CNC21</smiles>

(C) :<smiles>C[N+]12C=NC=CC=C1OCC2=O</smiles>

Figure 2. The potential encrgy curves for the angular variations from 5-menbercd spiro rings [(2)] to 6-meinbered rings [(B), (4)] through the states of (A) and (3), respectively. The angular values (X-axis) of the curves from (2) to (B) [ from (2) to (4)] are obtained from the variations of $\left(\angle \mathrm{N}_{7}-\mathrm{C}_{3}-\mathrm{C}_{2}\right)\left[\left(\angle \mathrm{O}_{4}-\mathrm{C}_{3}-\mathrm{C}_{3}\right)\right]$. The angular value (x-axis) of the curve from $(\mathrm{A})$ to $(\mathrm{c})$ is obtained from the variation of $\left(\angle \mathrm{N} 7-\mathrm{C}_{3}-\mathrm{C}_{4}\right)$.

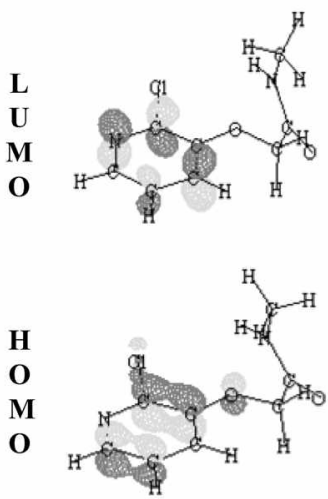

(1)
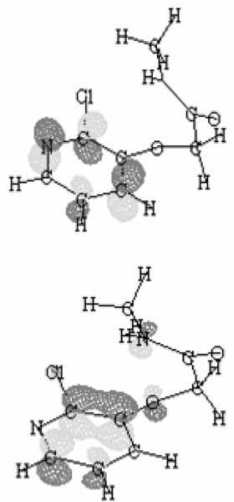

(1-a)
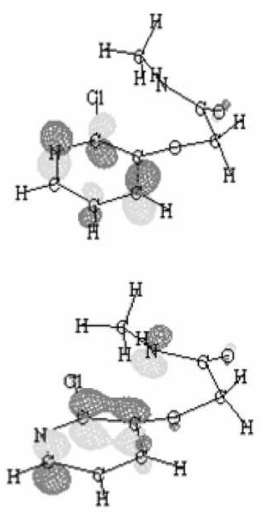

(1-b)
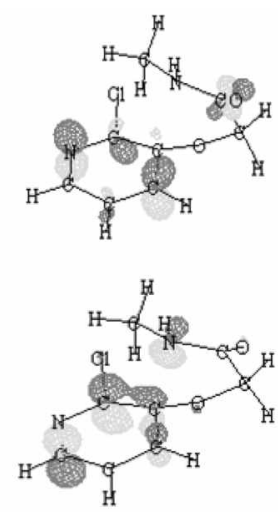

(1-c)
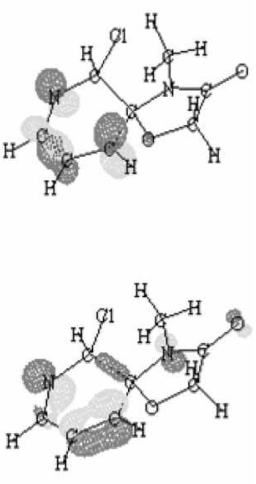

(2)

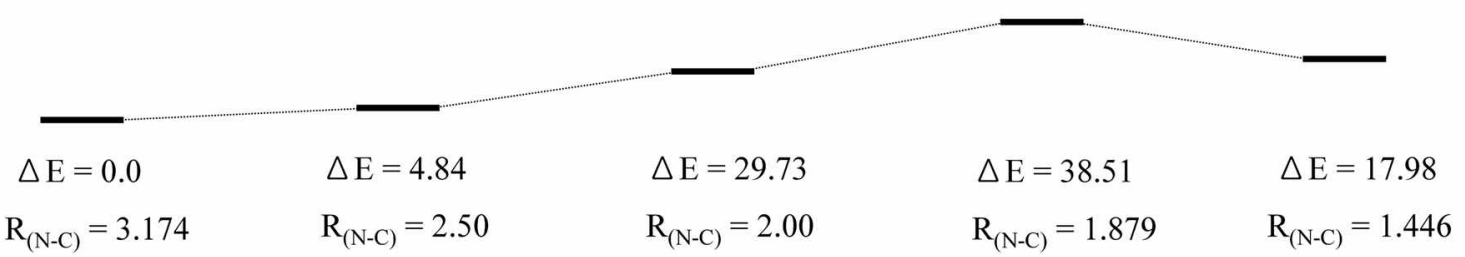

Figure 3. The optimized structures including the molecular orbitals for the cyclization reactions of $N$-methyl-2(2-chloropyridin-3-yloxy)

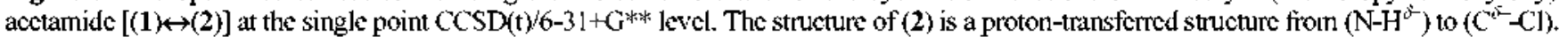

not optimized. The represented structure of $\left(\mathbf{3}^{\prime}\right)$ is drawn based on the result of a single point calculation at $\varphi=62.5$ degrees. At this angle, a concerted reaction occurs corresponding to the represented structure. That is, the $O$-bridgetype intermediate is instantaneously formed with two oxygen-carbon interactions and then immediately changes into (4). As a result, the reaction from $\left(2^{*}\right)$ to $(4)$ proceeds through the concerted mechanism. In these potential curves, the energy barrier $(1.38 \mathrm{kcal} / \mathrm{mol})$ from $\left(2^{*}\right)$ to $(\mathbf{A})$ is lower than that $(2.54 \mathrm{kcal} / \mathrm{mol})$ from $\left(2^{\prime}\right)$ to $\left(3^{\prime}\right)$. By the some experimental results, ${ }^{3-5,13-17}$ the some products of the Smiles rearrangement were observed in low yields under strong conditions (strong acid and high temperature) or the Smiles rearrangement did not take place under mild conditions. The reaction mechanisms for these reactions have not been explained in detail. The relative energy of (3) that is fomned through the concerted reaction is higher than that of $(\mathbf{A})$ which is formed through the stepwise mechanism. The relative energy gap $(28.35 \mathrm{kcal} / \mathrm{mol})$ between $\left(3^{*}\right)$ and $(4)$ is similar to that $(37.56 \mathrm{kcal} / \mathrm{mol})$ between (3) and (4) in Figure 1. The characteristic trends in Figure 2 are in good agreement with those in Figure 1.

The geometrical structures including the molecular orbitals and the relative energies for the cyclization reactions [(1) 
$\left.\rightarrow(2), \mathrm{R}_{\wedge 7 .<3}=3.174,2.50,2.00,1.879,1.446 \AA\right]$ are represented in Figure 3. To optimize the structure of the intermediate (2), the nitrogen atom $\left(\mathrm{N}_{7}\right)$ of the acetamide group is forced to approach the carbon atom $\left(\mathrm{C}_{3}\right)$ of the pyridine ring. As the intemuclear $\left(\mathrm{N}_{7} \cdots \mathrm{C}_{3}\right)$ distance decreases, the relative energies continuously increase. At $\mathrm{R}_{(\mathrm{N} 7 \mathrm{C} \cdot 3)}=1.879 \AA$, the transition state is formed. And the proton transfer takes place from $\left(\mathrm{N}-\mathrm{H}^{\delta+}\right)$ to $\left(\mathrm{C}^{i-}-\mathrm{Cl}\right)$, after which the intermediate (2) is optimized at $\mathrm{R}_{(\mathrm{N}-\mathrm{C})}=1.446 \AA$. In the acyclic structure of (1), the atomic charges of the $\mathrm{N}_{7}$ nitrogen and $C_{3}$ carbon are -0.764 and 0.286 au, respectively. As the internuclear $\left(\mathrm{N}_{7} \cdots \mathrm{C}_{3}\right)$ distance decreases, the overlap density of the $\pi$-HOMO on the pyridine decreases and the aromaticity caused by the overlap between the porbitals on the pyridine ring is broken. However, in the HOMO from (1) to (1-c), the lobes of carbon and nitrogen are enlarged. Finally, $\mathrm{a}\left(\mathrm{N}_{7} \cdots \mathrm{C}_{3}\right)$ bond is formed between the carbon and the nitrogen at (2), and the atomic charges of $\mathrm{N}_{7}$ and $C_{3}$ changes to -0.632 and 0.480 au, respectively. With the novel $\left(\mathrm{N}_{7} \cdots \mathrm{C}_{3}\right)$ bond formation, the atomic charges on the nitrogen and the carbon atoms become more positive. In (2), the p-orbitals on the pyridine ring overlap again with the neighboring $\mathrm{p}$-orbitals.

In the Smiles rearrangement, the cyclization reaction proceeds from the anionic acyclic reactant deprotonated by the base. To clarify the cyclization reaction paths, the potential energy curves from the neutral and the anionic acyclic reactants to their cyclic intermediates are shown in Figure 4. The potential curve from $(\mathbf{E})$ to $(\mathbf{F})$ corresponds to the cyclization caused by the $\left(\mathrm{N}^{-} \cdots \mathrm{C}_{3}\right)$ bond formation of the anionic reactant. The relative energy between the acyclic and the cyclic forms is nearly the same $(0.92 \mathrm{kcal} / \mathrm{mol})$. The energy gap $(10.37 \mathrm{kcal} / \mathrm{mol})$ between the acyclic form and the transition state is relatively low. Meanwhile, the two potential curves from (1) to (2) correspond to the cyclizations required for the $\left(\mathrm{N}_{7}-\mathrm{C}_{3}\right)$ bond formation from the neutral reactant. As the intenuclear $\left(\mathrm{N}_{7} \cdots \mathrm{C}_{3}\right)$ distance decreases, the potential energy increases from (1) to (P). Around $\mathrm{R}_{(\mathrm{N}-\mathrm{C})}=1.88 \AA$, the potential energy curve from (1) to (P) crosses with the curve from (Q) to (2). A transition state is formed and the proton transfer takes place from the nitrogen to the carbon $\left(\mathrm{N}-\mathrm{H}^{\delta+} \rightarrow \mathrm{C}^{\hat{i}-}-\mathrm{Cl}\right)$. After the proton transfer, the potential curve descends from $(\mathbf{Q})$ to $(2)$.

To examine the intermediate species [deprotonation by the base, the $\left(\mathrm{N}^{-} \cdots \mathrm{C}_{3}\right)$ bond formation and $(\mathrm{O} \cdots \mathrm{C})$ bond disconnection, and novel $(\mathrm{O} \cdots \mathrm{C})$ bond formation] for the previously suggested synthetic routes using the Smiles rearrangement in more detail, ${ }^{1-18}$ the potential energy curves for various $\left(\mathrm{O}_{4} \cdots \mathrm{C}_{3}\right)$ bond distances $(\mathrm{R}=1.3-2.9 \AA)$ at the B3P86/6-31+G** level are presented in Figure 5. In the cationic system, the potential curve for the variation of the $\left(\mathrm{O}_{4}-\mathrm{C}_{3}\right)$ bond distance is denoted as $(\mathrm{s}) \leftrightarrow(\mathrm{S})$. One of the 6membered rings of the cationic molecule [(s)] is broken at [bond $\left(\mathrm{O}_{4}-\mathrm{C}_{2}\right)$ ] resulting in its conversion to the 5-spiro molecule (S) through the formation of the [bond $\left.\left(\mathrm{O}_{4}-\mathrm{C}_{3}\right)\right]$. In the conversion from (s) to $(\mathbf{S})$, a transition state appears at $\mathrm{R}$ $=1.851 \AA$. The energy barrier from (s) to the transition state is $30.88 \mathrm{kcal} / \mathrm{mol}$. The $6-$ membered structure of (s) is more energetically stable than the 5 -membered structure of (S). In neutral reactants, the potential curve for the dissociation (ring opening) of the $\left(\mathrm{O}_{4}-\mathrm{C}_{3}\right)$ bond distance is denoted as $(t) \leftrightarrow(T)$. With increasing internuclear $\left(\mathrm{O}_{4} \cdots \mathrm{C}_{3}\right)$ distance, the potential energy curve from the neutral 5-spiro molecule $[(t)]$ to the acyclic $(\mathrm{T})$ structure dramatically increases. Meanwhile, the neutral potential curve for the $\left(\mathrm{O}_{4}-\mathrm{C}_{3}\right)$ bond formation is denoted as $(\mathbf{u}) \leftrightarrow(\mathrm{U})$. One of the 6-membered rings of $(\mathbf{u})$ is broken at the $\left[\left(\mathrm{O}_{4}-\mathrm{C}_{2}\right)\right.$ bond $]$ resulting in its conversion to the 5-spiro molecule $(\mathbf{U})$ through the formation of the $\left[\left(\mathrm{O}_{4}-\mathrm{C}_{3}\right)\right.$ bond $]$ and $\mathrm{a} \mathrm{Cl}^{-}$anion simultaneously moves from $\left(\mathrm{C}_{3}-\mathrm{Cl}\right)$ to $\left(\mathrm{C}_{2}-\mathrm{Cl}\right)$. Around $\left.\mathrm{R}_{4} \mathrm{O}_{4} \mathrm{C}_{3}\right)=1.898 \AA$, an energy barrier of $30.19 \mathrm{kcal} / \mathrm{mol}$ appears. The 5 -membered spiro structure of $(\mathbf{U})$ is more energetically stable than the

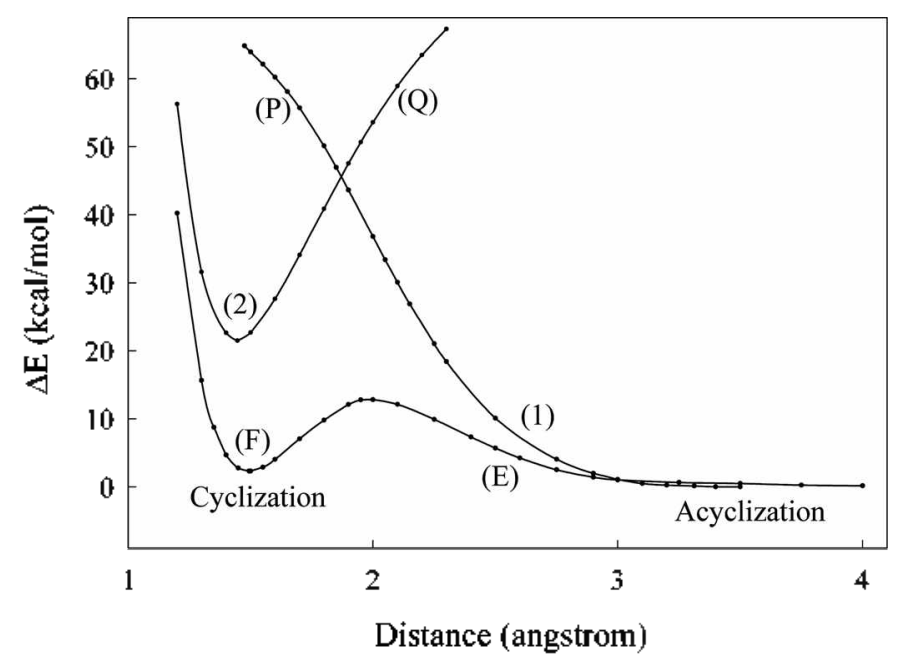

(1)

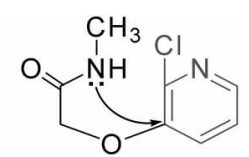

(P) :

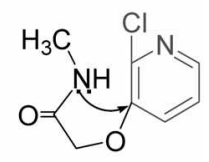

(Q) :

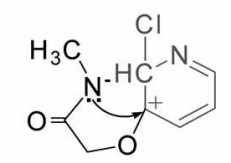

(2) :

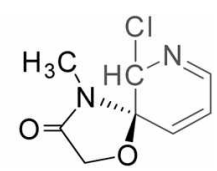

(E) :

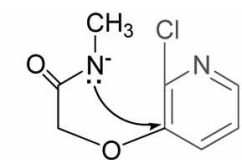

(F) :

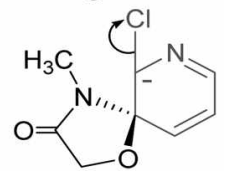

Figure 4. Potential energy curves for the bond formation from the acyclic molecule to the cyclic one at the MP2/6-3I+G** level. The potential curves from (1) to (2) correspond to a cyclization reaction process with the $\left(\mathrm{N} \cdots \mathrm{C}_{3}\right)$ bond formation of the neutral reactant. From $(\mathbf{P})$ to $(\mathbf{Q})$, the proton transfer occurs around $\mathrm{R}=1.875 \AA$. The curve from $(\mathbf{E})$ to $(\mathbf{F})$ also corresponds to a cyclization process by the $\left(\mathrm{N}^{-} \cdots\right.$ $C_{3}$ ) bond formation from the anionic reactant (Smiles rearrangenent). 

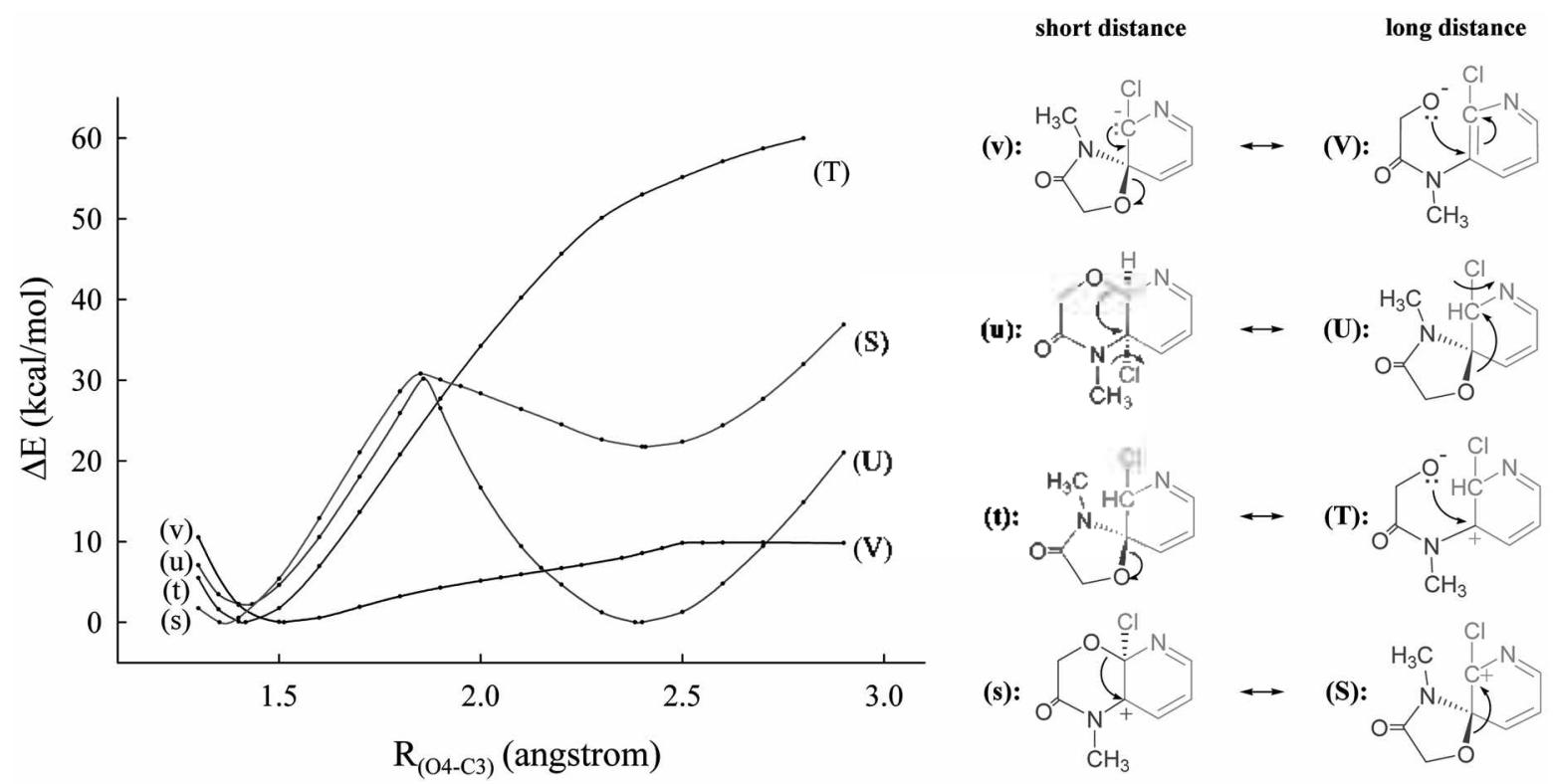

Figure 5. Potential energy curves for the variations of the $\left(\mathrm{O}_{4}-\mathrm{C}_{3}\right)$ bond distances after the Smiles rearrangenent at the $\mathrm{B} 3 \mathrm{P} 86 / 6-3 \mathrm{I}+\mathrm{G}^{* *}$ level. $(\mathbf{s}) \leftrightarrow(\mathbf{S})$ : variation of the $\left(\mathrm{O}_{4}-\mathrm{C}_{3}\right)$ bond distance in the cationic system. $(\mathbf{t}) \leftrightarrow(\mathbf{T})$ ) variation of the bond distance of $\left(\mathrm{O}_{4}-\mathrm{C}_{3}\right)$ in the neutral system. $(\mathbf{u}) \leftrightarrow(\mathrm{U})$ : variation of the bond distance of $\left(\mathrm{O}_{4}-\mathrm{C}_{3}\right)$ in the neutral system. $(v) \leftrightarrow(\mathrm{V})$ : variation of the $\left(\mathrm{O}_{4}-\mathrm{C}_{3}\right)$ bond distance in the anionic system.

6-membered structure of $(\mathbf{u})$. In the case of the anionic reactants proceeding through the Smiles rearrangement, the potential curve for the variation of the $\left(\mathrm{O}_{4}-\mathrm{C}_{3}\right)$ bond distance in the anionic 5 -spiro molecule is denoted as $(\mathrm{v}) \leftrightarrow(\mathrm{V})$. With increasing intenuclear $\left(\mathrm{O}_{4} \cdots \mathrm{C}_{3}\right)$ distance, the potential energy curve from $(v)$ to $(V)$ slowly increases.
The geometrical structures for the acyclic reactants leading to the conversion to their products were optimized with the some methods/6-31+G** $\left(6-31 G^{*}\right)$ basis set. The relative energies between these geometrical structures of the reactants, intermediates, transition states, and products are listed in Table 1. The relative energies calculated at the

Table 1. Relative energies ( $\mathrm{kcal} / \mathrm{mol}$ ) for the acyclic reactants leading to the conversion to their products at the some methods/6-31+G** $(6-$ $31 \mathrm{G}^{*}$ ) basis set

\begin{tabular}{|c|c|c|c|c|c|c|c|}
\hline \multirow[t]{2}{*}{ Relative Energy } & \multicolumn{2}{|c|}{$\mathrm{HF}$} & \multicolumn{2}{|c|}{ MP2 } & \multirow{2}{*}{$\begin{array}{c}\text { single point } \\
\operatorname{ccsD}(t) \\
6-31+G^{* * *}\end{array}$} & \multicolumn{2}{|c|}{ B3P86 } \\
\hline & $6-31 \mathrm{G}^{*}$ & $6-31+\mathrm{G}^{* \neq}$ & $6-31 G^{*}$ & $6-31+G^{* *}$ & & $6-31 \mathrm{G}^{*}$ & $6-31+\mathrm{G}^{\neq *}$ \\
\hline$\Delta E_{(C)-(1)}$ & 3.68 & 3.00 & 2.54 & 1.96 & 1.84 & 2.77 & 2.07 \\
\hline$\Delta \mathrm{E}_{(\mathrm{C})-(2)}$ & 26.96 & 26.27 & 21.89 & 20.05 & 19.82 & 22.58 & 20.51 \\
\hline$\Delta \mathrm{E}_{(\mathrm{C})-(\mathrm{Aj})}$ & 109.00 & 106.24 & 72.59 & 68.21 & 67.75 & 73.74 & 68.91 \\
\hline$\Delta \mathrm{E}_{(\mathrm{C}) \cdot(\mathrm{B})}$ & 65.45 & 61.53 & 57.38 & 53.70 & 53.46 & 56.00 & 54.39 \\
\hline$\Delta \mathrm{E}_{(\mathrm{C})-(\hat{3})}$ & 95.88 & 94.25 & 90.34 & 87.34 & 86.42 & 91.72 & 88.26 \\
\hline$\Delta E_{(C)-(+)}$ & 57.84 & 56.23 & 52.31 & 49.32 & 48.86 & 53.70 & 50.24 \\
\hline$\Delta E_{(C)-(5)}$ & 3.46 & 3.00 & 2.07 & 1.61 & 1.61 & 2.31 & 1.61 \\
\hline$\Delta \mathrm{E}_{(-2)}$ & 32.95 & 32.03 & 30.88 & 29.27 & 29.04 & 31.34 & 29.50 \\
\hline$\Delta \mathrm{E}_{(+) \cdot(\mathrm{b})}$ & 36.87 & 35.95 & 34.11 & 33.18 & 32.95 & 34.57 & 33.42 \\
\hline$\Delta \mathrm{E}_{(\ln (3)}$ & 34.11 & 32.95 & 30.42 & 29.50 & 29.27 & 30.65 & 29.73 \\
\hline$\Delta \mathrm{E}_{(\mathrm{B})(h)}$ & 43.55 & 44.71 & 15.21 & 14.51 & 14.52 & 17.74 & 14.52 \\
\hline$\Delta \mathrm{E}_{(\mathrm{B})(\mathrm{a}}$ & 29.50 & 27.65 & 27.42 & 25.81 & 25.58 & 27.88 & 26.04 \\
\hline$\Delta \mathrm{E}_{(+1+\mathrm{B}}$ & 7.61 & 5.30 & 5.07 & 4.38 & 4.60 & 2.30 & 4.15 \\
\hline$\Delta \mathrm{E}_{\text {unisi }}$ & 21.43 & 20.74 & 18.67 & 17.98 & 17.98 & 19.13 & 18.21 \\
\hline$\Delta \mathrm{E}_{(1)-(2)}$ & 23.28 & 23.27 & 19.35 & 18.09 & 17.98 & 19.81 & 18.44 \\
\hline$A E_{\text {(Tnd }}$ & 2.54 & 2.07 & 1.38 & 0.92 & 0.92 & 1.61 & 0.92 \\
\hline$\Delta \mathrm{E}_{(\mathrm{E}) \text { (G) }}$ & 14.29 & 13.60 & 11.75 & 10.37 & 10.37 & 12.21 & 10.83 \\
\hline$\Delta E_{(U)-(i \omega j)}$ & 5.07 & 4.38 & 3.00 & 2.31 & 2.31 & 3.00 & 2.31 \\
\hline$\Delta E_{(s)-(s)}$ & 27.42 & 25.58 & 23.51 & 21.89 & 21.66 & 23.97 & 22.35 \\
\hline
\end{tabular}


single point $\operatorname{CCSD}(t) / 6-31+\mathrm{G}^{* *}$ level are the smallest. The relative energies evaluated at the MP2/6-31+G** $\left(6-31 \mathrm{G}^{*}\right)$ level are similar to those at the B3P86/6-31+G** $\left(6-31 \mathrm{G}^{*}\right)$ level, respectively. The relative energies investigated at the $6-31+\mathrm{G}^{* *}$ basis set including the polarization and diffuse basis functions are smaller than those at the $6-31 \mathrm{G}^{*}$ basis set. These relative values are sensitive to the level of electron correlation and the size of the basis sets. As the correlation level and basis set enlarge, the energies decrease stepwise.

\section{Conclusions}

In conclusion, the reaction mechanisms for the cyclizations from $N$-methyl-2-(2-chloropyridin-3-yloxy)acetamide to 1-methyl-pyrido[3,2-b][1,4]oxazin-2-one and 1methyl-pyrido[2,3-b][1,4]oxazin-2-one were investigated using various theoretical methods. During the cyclization reactions, an important 5-membered spiro intermediate is first optimized from the acyclic reactant, and then proceeds to the 6-membered product through either the stepwise or concerted mechanism. In the stepwise mechanism (Path A), the $N$-bridge-type intermediate as a stable structure is optimized from the 5-membered intermediate and then proceeds step by step to 1-methyl-pyrido[3,2-b][1,4] oxazin2-one. However, in the concerted mechanism (Path B), 1methyl-pyrido[2,3- $b][1,4]$ oxazin-2-one is finally optimized from the 5-membered intermediate through the transient $O$ bridge-type structure. The $O$-bridge-type intermediate is not optimized on the potential curves. The relative potential energy curve of the stepwise mechanism is energetically lower than the corresponding curve of the concerted mechanism. The two cyclization reactions for the acyclic reactants proceed simultaneously through the bridge-type intermediate, (A) or (3), to form the heterocyclic product, (C) or (5), through the stepwise or concerted mechanism, respectively. Our suggested two mechanism paths (stepwise and concerted) for the cyclization reactions of the heterocycle-fused[1,4]oxazine derivatives are in good agreement with the previous experimental results produced with the synthetic routes (including Smiles rearrangement).

Acknowledgment. This research was supported by a grant (code\#: F0004021) from the Information Display R\&D Center, one of the 21 st Century Frontier R\&D Programs funded by the Ministry of Commerce, Industry and Energy of the Korean Government.

\section{References}

I. Macchiarulo, A.; Costantino, G.; Fringuelli, D.; Vecchiarelli, A.; Schiaffella, F.; Fringuelli, R, Bioorg. Med. Chem, 2002, 10, 3415.

2. Savelon, L.; Bizot-Espiard, J. G.; Caignard, D. H.; Pfeiffer, B.; Renard, P.; Viaud, M. C.; Guillaumet, G Bioorg. Med. Chem. $1998,6,133$.

3. Soukri, M.; Lazar, S.; Pujol, M. D.; Akssira, M.; Leger, J. M.; Jarry, C.; Guillaumet, G. Tetrahedron 2003, 59, 3665.

4. Soukri, M.; Lazar, S.; Akssira, M.; Guillaumet, Gi Org. Lett, 2005, 7,3629 .

5. Chezal, J. M.; Moreau, E.; Delmas, G; Gueifler, A.; Blache, Y; Grassy, G.; Lartigue, C.; Chavignon, O.; Teulade, J. C. J. Org. Chen. 2001, 66, 6576 .

6. Kundu, N. G.; Chaudhuri, G.; Upadhyay, A. J. Org. Chem. 2001, $66,20$.

7. Cho, S.-D.; Park, Y.-D.; Kim, J.-J.; Lee, S.-G; Ma, C.; Song, S.Y.; Joo, W.-H.; Falck, J. R.; Shiro, M.; Shin, D.-S.; Yoon, Y.-J. J. Org. Chem. 2003, 68,7918.

8. Cho, S.-D.; Song, S.-Y.; Park, Y.-D.; Kim, J.-J.; Joo, W.-H.; Shiro, M.; Falck, J. R.; Shin, D.-S.; Yoon, Y.-J. Tetrahedron Lett. 2003, 44,8995 .

9. Buckman, B.; Mohan, R.; Koovakkah, S.; Liang, A.; Trinh, L.; Mortissey, M. M. Bioorg. Med. Chem. Lett. 1998, 8, 2235.

10. Rao, U. N.; Biehl, E. J. Org. Chem. 2002, 67, 3409.

11. Bonini, C.; Funicello, M.; Scialpi, R.; Spagnolo, P. Tetrahedron $2003,50,7515$

12. Mizuno, M.; Yamano, M. Org. Lett. 2005, 7, 3629.

13. Balko, T. W.; Brinkmeyer, R. S. J. Heterocycl. Chem, 1987, 24 , 901 .

14. Heilmann, D.; Sicker, D.; Prakt, J. Chem. 1990, 332, 265.

15. Erickson, W. R.; McKennon, M. J. Tetrahedron Lett. 2000, 41, $454 \mathrm{I}$.

16. Kimbaris, A.; Cobb, J.; Tsakonas, G.; Varvounis, G. Tetrahedron 2004, 60, 8807

17. Rotas, G; Kimbaris, A.; Varvounis, G Tetrahedron 2004, 60, 10825.

18. Bacqué, E.; Qacemi, M. E.; Zard, S. Z. Org. Lett. $2005,7,3817$.

19. Manojkumar, T. K.; Suh, S. B.; Oh, S. K.; Cho, S. J.; Cui, C.; Zhang, X.; Kim, K. S. J. Org. Chem. 2005, 70, 2651.

20. Whangbo, M.-H.; Stewart, K. R. J. Org. Chem. 1982, 47, 736.

2I. Frish, M. J.; Trucks, G. W.; Head-Gordon, M. H.; Gill, P. M. W.; Wong, M. W; Foresman, J. B.; Johnson, B. G.; Schlegel, H. B.; Robb, M. A.; Replogle, E. S.; Gomperts, R.; Andres, J. L.; Raghavachari, K.; Binkley, J. S.; Gonzalez, C.; Martin, R. L.; Fox, D. J.; Defrees, D. J.; Baker, J.; Stewart, J. J. P.; Pople, J. A. Gatrssian 03; Gaussian Inc.: Pittsburgh. 2003.

22. Andzelm, J.; Wimmer, E.; Salahub, D. R. The Challenge of d-and f-Electrons: Theory and Complitation.; Salahub, D. R.; Zerner, M. C., Eds; ACS Symposium Series, ACS: Washington D. C., 1989.

23. Becke, A. D. Phys. Rev. 1988, A38, 3098.

24. Lee, C.; Yang, W.; Parr, R. G. Phss. Rev. 1988, B37, 785.

25. Perdew, J. P. Phys. Rev, 1986, B33, 8822.

26. Park, J. K.; Kim, B. G; Koo, I. S. Bill. Korean Chem. Soc. 2005, 26,1795 .

27. Park, J. K.; Kim, B. G. Bull. Korean Chem. Soc, 2006, 27, 1405. 